Digital Press Social Sciences and Humanities

The Model of Family Education in Developing Prosocial for Early Children on Playing in Public Facilities During Covid-19

Setiawati

Proceeding of Non-Formal Education International Seminar 2021

Alim Harun Pamungkas, Jamaris, Solfema (eds) 


\title{
The Model of Family Education in Developing Prosocial for Early Children on Playing in Public Facilities During Covid-19
}

\author{
Setiawati \\ Department of Non Formal Education Universitas Negeri Padang, Padang, Indonesia \\ e-mail: setiawatipls@fip.unp.ac.id
}

\begin{abstract}
This research is motivated by the low participation of parents in the development of children's prosocial activities in the arena of public facilities, which results in poor prosocial abilities of children. This can be seen from the behavior of early childhood who like to monopolize the game, not patiently waiting for their turn, likes to hit friends, and does not like friends, do not want to share and so forth. The purpose of this study was to describe the developing prosocial for Early children on playing in public facilities during Covid-19. This article design be Systematic literature Review (SLR): (1) Parents can develop children's prosocial behavior in the playground using adaptive model (a model adapted to the needs and age of the child), so that can be easily understood and adapted to the conditions of the child, parents, and existing playground equipment (2) Covid-19 has impacted children's social development, children interact less with others. Parents need to develop their children's prosocial in their daily activities at home and the playground (3) The providers of the public playground facilities and parents should strictly paying attention on health protocols, such as making sure the physical distancing, and providing proper hand washing facilities
\end{abstract}

\section{Keywords}

Model development, prosocial, family, covid-19

\section{Introduction}

The social development of children is affected by the family environment and the environment outside the house. The family environment is the first and main environmental influence on various aspects of child development, including social development (Hurlock, 2000; Napora, 2015). The prosocial experience of children at an early age is a starting point for children in creating a caring attitude towards others, a positive attitude (prosocial). If children gets a pleasant social experience, then they feel happy and behave socially, but if the child gets a less pleasant social experience, then anti-social behavior will develop and last until they get older (Hurlock, 2000).

Public play facilities which are in the midst of the community are a very strategic place in the development of children prosocial. This is in addition to children being faced with natural situations, interactions with peers, also the environment is very challenging and mutually interactive in both persuasive and competitive forms. This is consistent with the results of research conducted by Nurmalitasari (2015) that children's social development is obtained from maturity and learning opportunities from various environmental response

The results showed that parents had not participated in the social development of children in the public play arena. There are several reasons for parents why they do not carry out the prosocial development of their children, among them they argue that: (1) it is not yet time, the social development of children is done, because they are still too small. (2). Even if directed they don't understand, (3) there are parents who think that they don't know that social development needs to be done since the child is still small (4) There are parents who don't want to know about the situation, and they are more focused on children themselves. Suggestions in this study need to provide information to parents or caregivers about children's social development early on in the public play arena. 


\section{Methods}

This research is an ADDIE development model consisting of five stages: Analysis, Design, Development, Implementation, and Evaluation. Following the data results of needs assessments, a structured outline of the contents of the model produced a prototype model that has been validated, tested limited to small groups, and evaluation of each phase. The population for the trial subjects is all parents will bring their children to play in public play facilities in the complex Singgalang. The data analysis technique consisted of qualitative and quantitative analysis. The results showed that the development model of family education in early childhood development prosocial using the ADDIE development model consisting of the educational model prosocial family in early childhood development is already fit for use after rated valid, practical, and effective based on the criteria that have been set.

\section{Results and Discussion}

Social development of children is strongly influenced by the treatment process or the parental guidance in introducing the various aspects of social life, or the norms of social life, or encourage and provide an example to children, on how to implement these norms in everyday life. Child childhood social experience of the environment will affect the child's social behavior later as young adults(Ariati et al., 2018) . If childhood children experience less unpleasant or from the environment, then the child is likely to behave anti-socially, and vice versa, if the child can experience the excitement concerning the environment, then the child is likely to behave prosocially.

Facilities those are common to play a very strategic container in a child's social development. This is in addition to children exposed to the natural situation, interaction with peers, as well as the environment is very challenging and interactive with each other in the form of a persuasive and competitive. Education in the family is the first and foremost education for every child. This is largely attributable as a child, especially at an early age more are in households compared to outdoors. The purpose was to ensure that family education of children and family members can grow and develop as much as possible according to his ability (Azizah \& Kurniawati, 2013), to become an independent person in society and can be a productive man for himself and the environment.

At this stage, needs analysis (based on questionnaires) the importance of the family education model in the development of prosocial early childhood playground public facilities towards the better. Needs analysis concerns the application in the development of prosocial family education early childhood playground public facilities. The data was obtained through a questionnaire distributed to 20 elderly people. The object is the implementation and application of family education in the development of prosocial early childhood playground public facilities.

According to the table the distribution of the frequency distribution analysis of the needs of the above, it is known that the category is needed got a percentage of $2.86 \%$, the category takes a percentage $5.71 \%$, the category is quite taking a percentage $45.71 \%$, the category is less need for a percentage 28.57 , and the category has not required a percentage $17: 14 \%$. Based on these results, a category quite takes a percentage is highest among the other categories, so it takes a family educational model in the development of prosocial early childhood playground public property".

Based on the fact that the case above, it is necessary to develop a varied learning design in the educational process in the development of prosocial family early childhood playground public facilities. After a needs analysis was obtained then proceed with the design of the family education in child prosocial development.

In the design stage of the model development done drafting activities (blueprint) model based on the data obtained from analytical work. At this stage, the researchers designed the product in the form of a family education module in the development of prosocial early childhood playground public facilities.

After a needs analysis and identification of problems, the next module is designed for the development of prosocial family education in early childhood by parents. The module is a self-learning package which includes a series of learning experiences planned and systematically designed to help learners achieve learning objectives (Natsiopoulou, Vidali-Laloumi, Zachopoulou, \& Trevlas, 2010; Syaparuddin, 2020). In this study modules that are designed the only module on family education in the development of prosocial early childhood playground public facilities. 
In development doing product development. At this stage there are some steps taken by the researcher, namely: (a) conduct formative evaluation, (b) revise the prototype. The steps performed following that are described in the design stage.

The family education model development stage in the development of prosocial early childhood playground public facilities is an activity or process of realizing the design (blueprint) at the stage of conceptual design was shaped into products that are ready to be implemented. In accordance with the draft, the products developed in this research module in the development of prosocial family education early childhood playground public facilities. Once the module product family education for early childhood developed a kind of selection, then test the validity of the product. A validity test is done to determine whether the products developed invalid or that the benchmark for the appropriateness of use.

According to the table above, it can be concluded from the results of the validation by experts and practitioners as a whole book module prosocial family education in early childhood development in the arcades of public facilities to get an average of 4.27 or are in the category of very valid. The results of the expert validation to this book shows that the objectives, instructions for use, description of materials, the characteristics of the module, physical appearance and language education modules books prosocial family in early childhood development in the arcades of public facilities "are in the category of very valid. All validators consensus view is that this book deserves to be used with minor revisions, meaning that all aspects were judged on criteria that can be accepted, so it does not require major revision and revalidation.

The implementation stage is the stage where the products are developed and validated by a validator which was then revised as input and suggestions received, then applied in family education for young children. Implementation carried out her public play areas Singgalang Complex Block B. Padang in the form of limited testing. A limited trial was conducted to determine whether the model conforms with the expected goals before going on to the extended test. Before the model is implemented beforehand researchers provide insight to parents about the guidelines in the process module family education for young children in the playground of public facilities. Besides, parents are given all product development consists of educational modules books prosocial family in early childhood development arena play public facilities

. Based on the results of trials that have been done in Singgalang Complex Padang, the result is that the learning model prosocial family education in early childhood development in the arcades of public facilities can be carried out with an average of 4.47 or in the excellent category. Following the results of the trials conducted subsequently extended to the model of family education for young children.

The evaluation stage (assessment) is the last activity in developing a family education model in early childhood prosocial development. Following the ADDIE development model, not only evaluated the implementation of the model, but it is done at every step of model development.

In the design step, the researchers evaluated the problems that exist in family education for young children through a needs analysis is the basis in determining solutions to problems. Further evaluation is done at the design stage to determine and ascertain whether the design was developed following the problem at hand. At the development stage the researcher evaluates; 1 ) whether the model developed following the design, and 2) whether the developed model is valid or not. The evaluation was conducted by experts who then performed the revision of the products developed. All evaluations were performed on the stage of the analysis, design and development is a formative evaluation.

In addition to conducting formative evaluation, researchers also conducted a summative evaluation. Summative evaluation conducted on the implementation of the educational model for early childhood family that includes an evaluation of early childhood. The evaluation of the process aims to test the practicalities of family education evaluation models and aim to look at the effectiveness of the model.

Test carried out on the practicalities of the implementation phase to see the practicality of the product. Rate of practicalities of family education module for young children to be given to parents. Aspects of assessment practicalities module family education for young children by parents include: 1) aspect of the substance that includes objectives and indicators of family education for young children, the stages (syntax) modules, educational material family for early childhood, strategy and methods and time allocation. 2) technical aspects which includes the instructions and packaging modules and 3) aspects of language

According to the table above, it can be explained that the practicalities of module family in the development of prosocial early childhood playground public facilities by expert views on the practicalities of each grain of the aspects of assessment results obtained point 1 is very practical, item 2 practical, item 3 very practical, very practical item 4 , item 5 of thumb, point 6 of the practical, very practical item 7 and item 8 practical. Seen from the table above it can be concluded that the overall indicator of the 
importance of the evaluation aspects above-average ie 4.13 or are in the category of practical, then the book practicalities of family education module in prosocial development of early childhood playground practical declared public facilities and fit for use

According to the table above, it can be explained that theoretically a frequency of 8 with a small lowest score of 0:00 categorized as very cumbersome and large the highest score of 4.2 with very practical and practical categories. Based on the results of data analysis can be argued that the very practical category is a percentage of $50 \%$ with a frequency of 4 and the practical category as a percentage of $50 \%$ with a frequency of 4. Judging from the practicalities of data from the above table it books practicalities of family education in early childhood development prosocial on playground public facilities by experts is otherwise very practical and feasible for use.

The effectiveness of the educational model prosocial family in early childhood development in the arcades of public facilities by parents include an assessment of early childhood activeness in interacting. Rate liveliness in early childhood is done by filling a questionnaire by parents. Assessing the effectiveness of the model followed by testing through a quasi-experimental. This quasi-experimental study object is the difference between the model prosocial family education for early childhood and treatment associated with the conventional model prosocial early childhood development. This quasi-experimental study aims to look at the model used advantages compared with conventional models. Therefore in this section are presented the results of a quasi-experimental study of the educational model prosocial family in early childhood development.

Is shown in Table $\mathrm{t}$ for $\mathrm{df} 20 \mathrm{on}$ the real level of 0.05 is 172 . Based on the results of the t-test on the result that $t>t$ table is $3.470>1.72$ and a significance level of $<0.05$ is 0.000 , it can be concluded that hypothesis $\mathrm{H} 1$ is accepted or $\mathrm{H} 0$ is rejected. It can be concluded that there is a significant difference in prosocial early childhood development between experimental class module using prosocial family education compared with controls without the module class family education in early childhood development prosocial.

\section{Conclusions}

Based on the results of the development of the educational model prosocial family in early childhood development can be deduced as follows:

a. The prosocial behavior of children in the playing arena has not reflected the prosocial direction, both quantitatively and qualitatively. Parents in accompanying children to play were more following the child's wishes than give children the opportunity to socialize with their friends, such as playing with their cellphones, and chat with their parents.

b. The existing family education model in the prosocial development of early childhood is valid, practical and effective based on predetermined criteria.

c. There is a change in the behavior of early childhood in the public playground facilities and at home from anti-social to pro-social behavior. It can be seen that in general they are more willing to share, cooperate, taking turns, to negotiate and to help others

\section{References}

Ariati, N. N., Fetria, A., Purnamawati, A. A. P., Suarni, N. N., Padmiari, I. A. E., \& Sugiani, P. P. S. (2018). Description of nutritional status and the incidence of stunting children in early childhood education programs in Bali-Indonesia. Bali Medical Journal, 7(3). https://doi.org/10.15562/bmj.v7i3.1219

Azizah, N., \& Kurniawati, Y. (2013). Personal Hygiene Learning in Preschool Classroom. Indonesian Journal of Early Childhood, 2(2), 50-57.

Hurlock, E. B. (2000). Psikologi Perkembangan. Jakarta: Erlangga.

Napora, E. (2015). Factors Affecting Socialization from the Perspective of the Study of a School Child. 2(463), 135-143. https://doi.org/10.17770/sie2015vol2.463 
Natsiopoulou, T., Vidali-Laloumi, E., Zachopoulou, E., \& Trevlas, E. (2010). An innovative preschool health education program. Health Science Journal, 4(2), 110-117.

Nurmalitasari, F. (2015). Perkembangan Sosial Emosi pada Anak Usia Prasekolah. Buletin Psikologi, 23(2), 103-111.

Syaparuddin, S. (2020). Peranan Pendidikan Nonformal Dan Sarana Pendidikan Moral. Jurnal Edukasi Nonformal, 1(1), 173-186. 